ARTIGOS

\title{
ANÁLISE DOS PROPÓSITOS DE PRÁTICAS DE RESPONSABILIDADE SOCIAL EMPRESARIAL DE INDÚSTRIAS CEARENSES PARTICIPANTES DO PRÊMIO SESI DE QUALIDADE NO TRABALHO ${ }^{1}$
}

\section{RESUMO}

Este trabalho tem como objetivo principal analisar os propósitos de práticas de Responsabilidade Social de indústrias cearenses participantes do Prêmio SESI de Qualidade no Trabalho (PSQT); trata-se de empresas que: a) decidiram concorrer a um prêmio que avalia suas práticas sob a perspectiva da Responsabilidade Social; b) deram-se ao trabalho, para concorrer a tal prêmio, de escrever e submeter suas próprias práticas de Responsabilidade Social e; c) puderam ter suas práticas acessadas e utilizadas como objeto de pesquisa documental e análise de conteúdo neste trabalho. Com isso, encontrou-se como resultado principal que as indústrias pesquisadas se inspiram pelos propósitos recomendados pela teoria, mas quase sempre os adaptam às perspectivas dos acionistas.

Palavras-chave: Responsabilidade social empresarial. Desenvolvimento sustentável. Acionistas. Partes interessadas.

\footnotetext{
Raphael de Jesus Campos de Andrade contato@raphaelcampos.com Doutorando em Administração e Controladoria pela Universidade Federal do Ceará - Fortaleza - CE - BR
}

Laodicéia Amorim Weersma laoweersma@gmail.com Doutoranda em Gestão de Empresas e Inovação pela Universidade de Coimbra Portugal

\author{
Eleazar de Castro Ribeiro \\ coordadministracao01@ \\ unichristus.edu.br \\ Doutor em Educação pela \\ Universidade Federal do \\ Ceará. Coordenador do Curso \\ de Administração do Centro \\ Universitário Christus - \\ Fortaleza - CE - BR
}

\section{INTRODUÇÃO}

Embora a manifestação da Responsabilidade Social Empresarial (RSE) seja um fenômeno recente na história da Administração, sua evolução não deixa dúvida de que está, de fato, sendo incorporada aos modelos e às práticas de gestão empresarial (ALVES, 2003).

Observa-se o grande número de projetos desenvolvidos pelas empresas a fim de legitimar suas ações perante a sociedade. As organizações procuram explorar esse conceito, no sentido de se manterem firmes e atuantes no mercado, pois tal iniciativa passou a ser apontada como uma das principais credenciais para o desempenho positivo nos negócios (CAMPOS FILHO; PEREIRA, 2007).

As definições e proposições sobre Responsabilidade Social Empresarial variam de acordo com o contexto em que são criadas. Na medida em que se apresentam novos obstáculos ao desenvolvimento da economia, observa-se a multiplicação de abordagens quanto ao papel das organizações na sociedade (CAMPANARIO; MORETTI, 2009). 
Garriga e Melé (2004) afirmam que os modelos conceituais que tratam da RSE apresentam diferentes perspectivas em função da variedade de autores e de demandas históricas.

Tais perspectivas, naturalmente, complementam-se e se contrapõem entre si, evidenciando a busca contínua das organizações, da sociedade e da academia pela atuação empresarial socialmente responsável (CAMPOS FILHO; PEREIRA, 2007).

Por outro lado, nota-se que, diante dessa diversidade e divergência de proposições teóricas e metodológicas e das recorrentes cobranças sociais, muitas empresas no mundo inteiro, quando optam por atuar de forma socialmente responsável, não sabem muito bem por onde começar e no que investir, adotando práticas assistencialistas, sem qualquer relação com o core business e/ou obtendo impactos modestos ou sequer mensurados (KRAMER; PORTER, 2002, 2006).

De fato, não faltam estudos capazes de retratar os níveis de compreensão e maturidade das empresas no tocante à questão da Responsabilidade Social. De maneira geral, sabe-se como as empresas estão - inclusive de forma comparada umas com as outras, a partir de levantamentos, estudos múltiplos de casos, rankings e premiações nacionais e internacionais, dentre outras estratégias. Entretanto, não se encontram na literatura especializada questionamentos acerca do que as empresas querem (!) ao se envolverem com a temática em questão.

Este trabalho tem como objetivo principal analisar os propósitos de práticas de Responsabilidade Social das empresas; mais especificamente, de 52 indústrias cearenses participantes do Prêmio SESI de Qualidade no Trabalho (PSQT) em 2012.

Trata-se de um estudo que se justifica na medida em que evidencia demandas e boas práticas, recomenda melhorias à luz da literatura especializada e orienta a oferta de serviços de consultoria e a elaboração de políticas públicas de desenvolvimento sustentável.

A escolha de indústrias participantes do PSQT se deu em razão dos seguintes motivos: a) São empresas que decidiram concorrer a um prêmio que avalia suas práticas sob a perspectiva da Responsabilidade Social;

b) São empresas que, para concorrer a tal prêmio, deram-se ao trabalho de escrever e submeter suas próprias práticas de Responsabilidade Social e;

c) Tais práticas escritas e submetidas ao PSQT puderam ser acessadas e utilizadas como objeto de pesquisa documental e análise de conteúdo neste trabalho, que, além desta Introdução, está, enfim, estruturado em mais seis capítulos.

O segundo capítulo diz respeito à evolução histórica do conceito de Responsabilidade Social Empresarial - da Teoria do Acionista aos movimentos pelo Desenvolvimento Sustentável - e às proposições mais recentes de Organizações Sustentáveis. O terceiro capítulo, no sentido de se constituir os fundamentos teóricos para a análise dos dados, trata dos objetivos decorrentes das práticas de Responsabilidade Social recomendadas pela literatura especializada como um todo e, de forma sintética e justificada, pela ISO 26000 em particular. O quarto capítulo discorre sobre os aspectos metodológicos da pesquisa. O quinto capítulo analisa as práticas das indústrias cearenses à luz dos fundamentos teóricos do segundo capítulo e apresenta os resultados encontrados quanto aos objetivos e à eficácia organizacionais. Por fim, no sexto capítulo, são feitas as considerações finais.

\section{RESPONSABILIDADE SOCIAL EMPRESARIAL: DA TEORIA DO ACIONISTA ÀS ORGANIZAÇÕES SUSTENTÁVEIS}

As definições acerca da Responsabilidade Social Empresarial não demonstram pleno consenso teórico em função do contexto sociocultural e econômico em que cada uma delas foi concebida (CAMPOS FILHO; PEREIRA, 2007).

Para Gomes e Moretti (2007), trata-se de uma área polissêmica, com ampla profusão de significados para os conceitos utilizados. Dessa 
forma, torna-se imprescindível reconhecer as bases de conhecimento sobre as quais o campo se fundamenta.

A literatura sobre Responsabilidade Social é mais evidente nos Estados Unidos, em grande parte como produto do século XX, especialmente dos últimos 60 anos. A publicação "Responsabilidades Sociais do Homem de Negócios", de 1953, de Howard Bowen, é tida como um marco inicial da literatura moderna sobre o assunto (CARROLL, 1999).

As proposições de Bowen estavam fortemente ligadas ao cunho religioso e à compatibilidade das ações empresariais com a moral e com os valores da sociedade norte-americana daquela época (ALVES, 2003).

No início da década de 1960, Keith Davis estabeleceu sua definição de responsabilidade social argumentando que se trata de decisões e ações dos homens de negócios tomadas por razões para além do interesse legal, econômico ou técnico da empresa (CARROLL, 1999).

Uma discussão contrária à consideração de posicionamentos sociais responsáveis por parte da empresa partiu de Friedman (1970), que, em seu artigo "The Social Responsibility of Business Is to Increase Its Profits", publicado no The New York Times, pontuava que o único objetivo da empresa deveria ser a maximização do lucro para os acionistas.

O autor defendia que a preocupação social por parte dos administradores poderia arruinar as bases da sociedade livre.

Segundo Barbieri e Cajazeira (2009, p. 10), a Responsabilidade Social Empresarial só começa realmente a se consolidar como um tema relevante da Administração a partir da polêmica iniciada com o posicionamento de Friedman sobre o papel social da empresa:

[...] se a empresa está tendo lucro dentro da lei é porque está produzindo um bem ou serviço socialmente importante e, com isso, ela pode remunerar os fatores de produção (capital e trabalho), gerando renda para a sociedade e impostos para os governos que, estes sim, devem aplica-los para resolver problemas sociais, sendo os mais indicados para isso. Qualquer aplicação de recursos da empresa que não seja para a geração de lucros é condenada por ele.

Para Friedman, as doações e contribuições empresariais para outras finalidades que não sejam a de gerar tanto dinheiro quanto possível aos acionistas constituem uso impróprio de recursos (MCWILLIAMS; SIEGEL, 2001).

Ele não nega, portanto, a filantropia como uma atividade socialmente relevante, desde que seja provida com recursos dos indivíduos que são os proprietários das empresas (CARROLL, 1999).

Esse posicionamento passou a ser considerado como Teoria do Acionista e deu o tom para o debate sobre a Responsabilidade Social Empresarial, seja para apoiá-la, seja para combatê-la (BARBIERI; CAJAZEIRA, 2009).

Em contraposição à Teoria do Acionista, a compreensão de Carroll (1979) sobre Responsabilidade Social Empresarial ainda constitui a base de muitos programas e modelos de gestão contemporâneos e engloba expectativas econômicas, legais, éticas e filantrópicas que a sociedade tem em relação às organizações em dado período.

Para ser considerada socialmente responsável, portanto, a empresa deve, ao mesmo tempo, ser lucrativa, obedecer às leis, atender as expectativas da sociedade e ser boa cidadã.

Outro modelo que se contrapõe à Teoria do Acionista e que tomou grande impulso com as abordagens de gestão baseadas na visão sistêmica, na medida em que enfatiza o ambiente das empresas como constituído de diferentes segmentos da sociedade com expectativas e interesses próprios, é o modelo da Teoria dos Stakeholders (pessoas ou grupos com interesse na empresa ou que afetam ou são afetados por ela).

A sobrevivência da empresa no longo prazo seria obtida mediante a gestão balanceada das expectativas das partes interessadas, como clientes, fornecedores, funcionários, autoridades governamentais, comunidades locais, os próprios acionistas, dentre outros (KAMEL; RESENDE, 2007). 
A responsabilidade social exclusivamente centrada na geração de lucros, salários e impostos já não é mais suficiente para orientar os negócios diante de novos valores requeridos pela sociedade, como a busca pela qualidade de vida, a valorização do ser humano e o respeito ao meio ambiente (FREEMAN, 1984).

A Teoria dos Stakeholders, portanto, explora a inter-relação entre Responsabilidade Social Empresarial e os aspectos e impactos econômicos, ambientais e sociais das atividades produtivas, o que a associa ao tema do Desenvolvimento Sustentável, constituindo, assim, o conceito de Organizações Sustentáveis (BARBIERI; CAJAZEIRA, 2009).

Entre os modelos concebidos para integrar à gestão empresarial o conceito de sustentabilidade, destaca-se o Triple Bottom Line (tríplice linha de resultados líquidos), popularizado no ambiente empresarial com o livro Cannibals with forks, de John Elkington, publicado em 1997.
O uso da linguagem de resultados líquidos é familiar no ambiente empresarial, acostumado desde a sua origem a buscar resultado líquido na forma de lucro, resultado este que a contabilidade consagrou como a última linha da demonstração dos resultados dos exercícios financeiros (bottom line), agora acrescido de resultados sociais e ambientais (ELKINGTON, 2001).

Para as empresas, a incorporação desse modelo significa adotar estratégias de negócios e atividades que atendam as necessidades das empresas e dos seus Stakeholders atuais, enquanto protegem, sustentam e aumentam os recursos humanos e naturais que serão necessários no futuro (BARBIERI; CAJAZEIRA, 2009).

A Figura 1 abaixo apresenta, de forma sintética e cronológica, os marcos teóricos supracitados da Responsabilidade Social Empresarial.

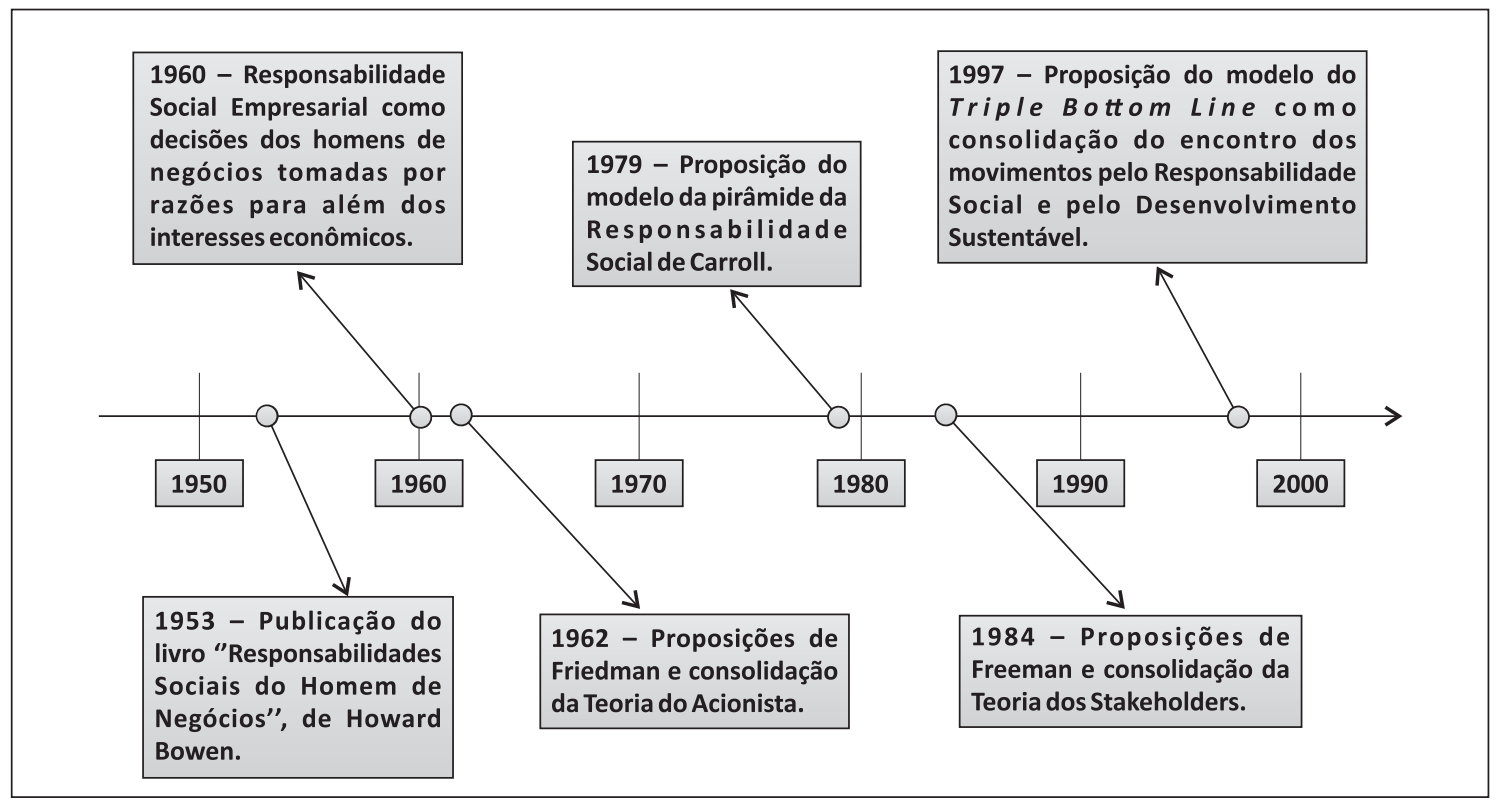

Figura 1 - Marcos teóricos da Responsabilidade Social Empresarial Fonte: adaptado de Garriga e Melé (2004).

Atualmente, não faltam iniciativas empresariais locais, regionais, nacionais e internacionais, na forma de diretrizes, normas de gestão voluntárias e outros instrumentos administrativos e operacionais que tentam traduzir as perspectivas dos movimentos de Responsabilidade Social e de Desenvolvimento Sustentável, isto é, de Organizações Sustentáveis, conforme detalhamentos do capítulo a seguir. 


\section{PROPÓSITOS DAS PRÁTICAS DE RESPONSABILIDADE SOCIAL EMPRESARIAL}

Grosso modo, conforme anteriormente assinalado e, em seguida, sintetizado pela Figura 3 , as empresas, em termos de propósitos de Responsabilidade Social, buscaram histórico-cronologicamente:

a) Maximizar lucros para seus acionistas sem descumprir a lei vigente;

b) Promover ações de filantropia em resposta às primeiras críticas recebidas dos acadêmicos e da sociedade;

c) Adotar modelos de gestão atentos não somente às questões econômicas, mas também legais, éticas e filantrópicas; d) Considerar não apenas os interesses dos acionistas, mas promover o equilíbrio entre os interesses de todas as partes interessadas e;

e) Satisfazer as necessidades econômicas, sociais e ambientais da geração presente sem comprometer as demandas das gerações futuras.

Tais objetivos, especialmente aqueles decorrentes da Teoria dos Stakeholders e do Triple Bottom Line, desdobraram-se em dezenas de modelos, ferramentas e práticas de gestão com objetivos específicos correspondentes, representados de forma simplificada pela Figura 2 logo abaixo.
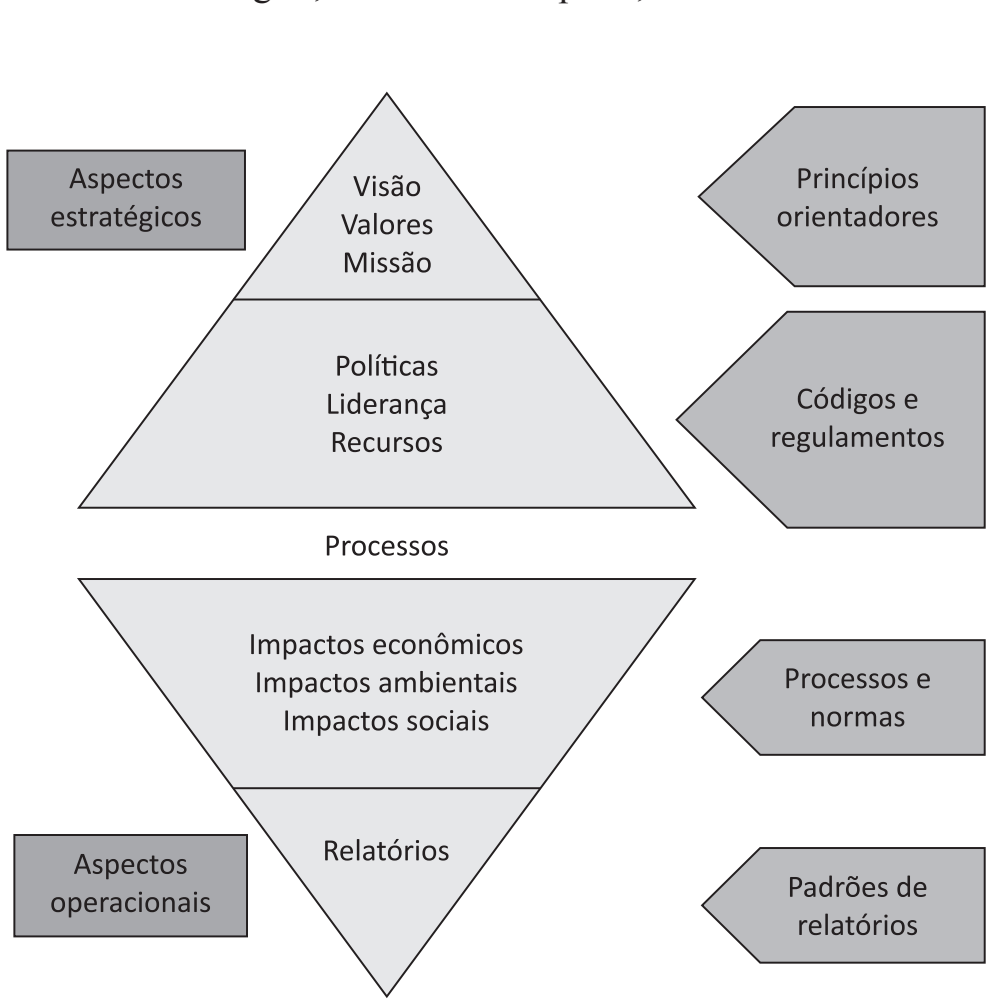

Declaração universal dos Direitos do Homem; Agenda 21; Carta da Terra; Metas do Milênio; Pacto Global.

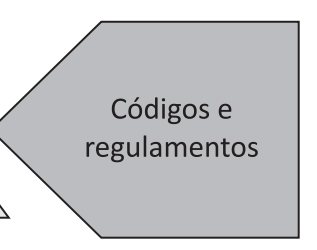

Convenções da OIT; Acordos multilaterais e regionais específicos; Diretrizes da OCDE para as multinacionais; Convenções contra corrupção.

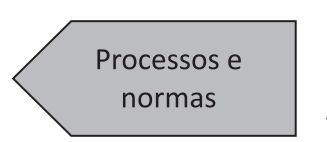

ISO 9001; ISO 14001; OSHA 18001; NBR 16001 AA 1000; SA 8000; PNQ.

Padrões de Balanço social; GRI; relatórios Indicadores Ethos; ISO 14063.

Figura 2 - Modelos, ferramentas e práticas de RSE Fonte: adaptado de Barbieri e Cajazeira (2009, p. 142).

Devido à sua generalidade e aplicabilidade, características deliberadamente buscadas por seu grupo de trabalho, formado por representantes de mais de 90 países e mais de
40 organizações internacionais e regionais de diferentes segmentos da sociedade (consumidores, governos, indústria, trabalhadores, organizações não governamentais, serviço, suporte, 
pesquisa e outros), a ISO 26000, que traz orientações sobre conceitos, princípios, práticas e temas da Responsabilidade Social para todos os tipos de organizações, pode ser entendida como capaz de sintetizar em si os elementos de gestão apontados pela Figura 2, podendo, portanto, constituir definitivamente os fundamentos teóricos de análise dos dados a serem coletados na etapa empírica deste trabalho, conforme detalhado na Figura 3 abaixo.

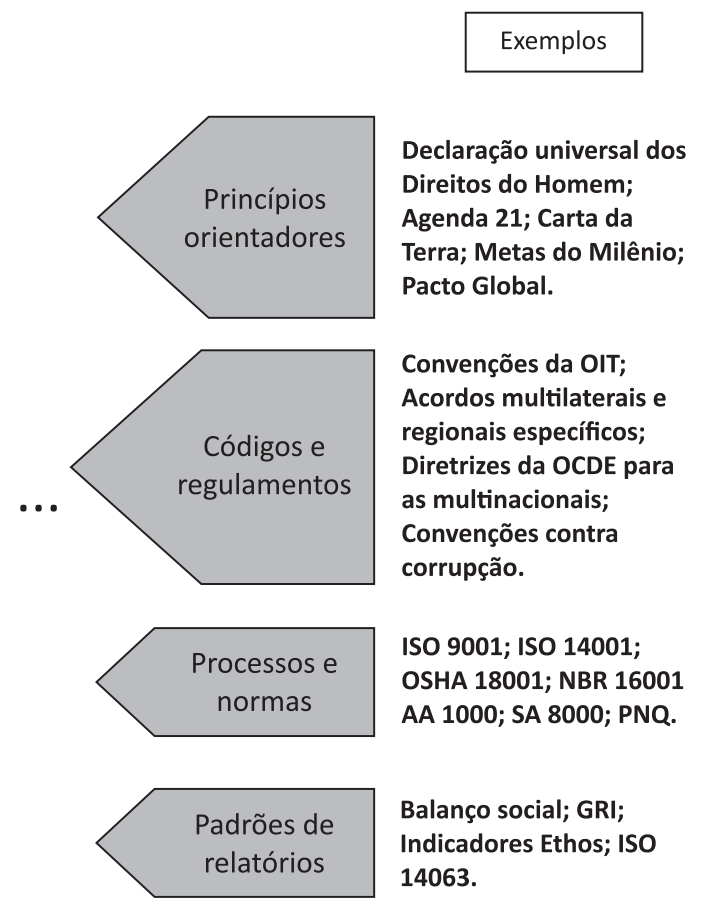

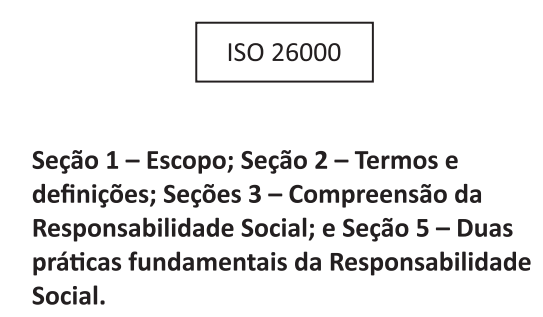

Seção 6 - Temas centrais da Responsabilidade Social.
Seção 7 - Integração da Responsabilidade Social em toda a organização.

Figura 3 - Modelos, ferramentas e práticas de RSE integrados à ISO 26000

Fonte: adaptado de Barbieri e Cajazeira (2009, p. 201).

A partir de rigorosa revisão bibliográfica, pode-se, enfim, deduzir das seções da ISO 26000 e dos elementos que as constituem os possíveis propósitos de Responsabilidade Social presentes na literatura e recomendados para as organizações como finalidades estratégicas a serem perseguidas por meio de suas práticas.

O Quadro 1 abaixo traz consigo tais propósitos de Responsabilidade Social Empresarial, que passam a constituir as categorias de análise da etapa empírica deste trabalho, cujos detalhes estão no capítulo de Metodologia logo a seguir.

\begin{tabular}{|l|l|l|}
\hline Seções da ISO 26000 & \multicolumn{1}{|c|}{$\begin{array}{c}\text { Elementos constituintes das } \\
\text { seções }\end{array}$} & $\begin{array}{c}\text { Propósitos de Responsabilidade Social } \\
\text { correspondentes }\end{array}$ \\
\hline 1. Escopo & $\begin{array}{l}\text { Orientações para organizações de } \\
\text { todo tipo, independentemente de } \\
\text { seu tamanho ou localização. }\end{array}$ & \\
\cline { 1 - 2 } 2. Termos e definições & Definição de termos-chave. & $\begin{array}{l}\text { Compreender a área de Responsabilidade } \\
\text { Social Empresarial. }\end{array}$ \\
\cline { 1 - 2 } 3. Compreensão da Res- & $\begin{array}{l}\text { História e características. } \\
\text { ponsabilidade Social }\end{array}$ & $\begin{array}{l}\text { Relacionamento entre Responsa- } \\
\text { bilidade Social e Desenvolvimen- } \\
\text { to Sustentável. }\end{array}$ \\
\hline
\end{tabular}




\begin{tabular}{|c|c|c|}
\hline \multirow{7}{*}{$\begin{array}{l}\text { 4. Princípios da Respon- } \\
\text { sabilidade Social }\end{array}$} & Accountability. & Responsabilizar-se por suas ações. \\
\hline & Transparência. & Ser transparente em suas decisões e atividades. \\
\hline & Comportamento ético. & Comportar-se eticamente. \\
\hline & $\begin{array}{l}\text { Respeito pelos interesses das par- } \\
\text { tes interessadas. }\end{array}$ & $\begin{array}{l}\text { Respeitar os interesses de suas partes inte- } \\
\text { ressadas. }\end{array}$ \\
\hline & Respeito pelo Estado de direito. & $\begin{array}{l}\text { Conhecer e cumprir a lei e os regulamentos } \\
\text { aplicáveis. }\end{array}$ \\
\hline & $\begin{array}{l}\text { Respeito pelas normas internacio- } \\
\text { nais de comportamento. }\end{array}$ & $\begin{array}{l}\text { Respeitar as normas internacionais de com- } \\
\text { portamento. }\end{array}$ \\
\hline & Respeito pelos direitos humanos. & Respeitar os direitos humanos. \\
\hline \multirow{2}{*}{$\begin{array}{l}\text { 5. Duas práticas funda- } \\
\text { mentais da Responsabi- } \\
\text { lidade Social }\end{array}$} & $\begin{array}{l}\text { Reconhecimento da Responsabili- } \\
\text { dade Social. }\end{array}$ & $\begin{array}{l}\text { Reconhecer como legítimos os princípios } \\
\text { da Responsabilidade Social. }\end{array}$ \\
\hline & $\begin{array}{l}\text { Identificação e engajamento das } \\
\text { partes interessadas. }\end{array}$ & Identificar e engajar as partes interessadas. \\
\hline \multirow{7}{*}{$\begin{array}{l}\text { 6. Temas centrais da } \\
\text { Responsabilidade Social }\end{array}$} & Governança organizacional. & $\begin{array}{l}\text { Decidir com base nos princípios de Respon- } \\
\text { sabilidade social. }\end{array}$ \\
\hline & Direitos humanos. & Respeitar os direitos humanos. \\
\hline & Práticas de trabalho. & Oferecer condições dignas de trabalho. \\
\hline & Meio ambiente. & $\begin{array}{l}\text { Mitigar os impactos ambientais de suas de- } \\
\text { cisões e atividades. }\end{array}$ \\
\hline & Práticas leais de operação. & Operar de forma leal com as partes interessadas. \\
\hline & Questões relativas ao consumidor. & $\begin{array}{l}\text { Oferecer informações precisas e contratos } \\
\text { justos e promover a acessibilidade de pro- } \\
\text { dutos e o consumo sustentável. }\end{array}$ \\
\hline & $\begin{array}{l}\text { Envolvimento e desenvolvimento } \\
\text { da comunidade. }\end{array}$ & $\begin{array}{l}\text { Envolver e desenvolver a comunidade onde } \\
\text { opera. }\end{array}$ \\
\hline \multirow{7}{*}{$\begin{array}{l}\text { 7. Integração da Res- } \\
\text { ponsabilidade Social em } \\
\text { toda a organização }\end{array}$} & $\begin{array}{l}\text { Relação das características da or- } \\
\text { ganização com a Responsabilida- } \\
\text { de Social. }\end{array}$ & $\begin{array}{l}\text { Identificar a propensão organizacional para } \\
\text { a Responsabilidade Social. }\end{array}$ \\
\hline & $\begin{array}{l}\text { Compreensão da Responsabilida- } \\
\text { de Social da organização. }\end{array}$ & $\begin{array}{l}\text { Identificar os impactos de suas decisões e } \\
\text { atividades. }\end{array}$ \\
\hline & $\begin{array}{l}\text { Iniciativas voluntárias de Respon- } \\
\text { sabilidade Social }\end{array}$ & Estabelecer programas de voluntariado. \\
\hline & $\begin{array}{l}\text { Fortalecimento da credibilidade } \\
\text { em relação à Responsabilidade } \\
\text { Social. }\end{array}$ & $\begin{array}{l}\text { Obter o reconhecimento da sociedade por } \\
\text { suas práticas socialmente responsáveis. }\end{array}$ \\
\hline & $\begin{array}{l}\text { Análise e aprimoramento das } \\
\text { ações e práticas da organização } \\
\text { relativas à Responsabilidade So- } \\
\text { cial. }\end{array}$ & $\begin{array}{l}\text { Obter resultados eficazes com as ações de } \\
\text { Responsabilidade Social. }\end{array}$ \\
\hline & $\begin{array}{l}\text { Comunicação sobre Responsabili- } \\
\text { dade Social }\end{array}$ & $\begin{array}{l}\text { Informar e conscientizar as partes interessa- } \\
\text { das quanto à Responsabilidade Social. }\end{array}$ \\
\hline & $\begin{array}{l}\text { Práticas para integrar a Responsa- } \\
\text { bilidade Social em toda a organi- } \\
\text { zação. }\end{array}$ & $\begin{array}{l}\text { Desenvolver competências internas para a } \\
\text { Responsabilidade Social. }\end{array}$ \\
\hline
\end{tabular}

Quadro 1 - Propósitos de Responsabilidade Social deduzidos da ISO 26000

Fonte: elaborado pelos autores (2014).

Tratam-se, portanto, considerando a dupla ocorrência do propósito "respeitar os direitos humanos", de 23 propósitos de Responsabilidade
Social Empresarial, que possuem uma característica em comum: não estão colocados como meios para o alcance de outros objetivos para a empresa, 
seus proprietários e dirigentes, mas como fins em si mesmos, como valores a serem primeiramente internalizados e, em seguida, buscados e preservados de forma estratégica, por meio de gestão (BARBIERI; CAJAZEIRA, 2009).

Tais propósitos são específicos de um propósito ainda maior da ISO 26000 e da Responsabilidade Social: maximizar a contribuição da organização para o desenvolvimento sustentável.

O propósito "obter o reconhecimento da sociedade por suas práticas socialmente responsáveis", por exemplo, não se refere - como Kramer e Porter $(2002,2006)$ apontam como práticas comuns - a atitudes cosméticas, mas à ideia de inspirar boas práticas, de gerar orgulho e sentimento de pertença nas partes interessadas. Tratam-se, enfim, de propósitos teóricos ideais, que servirão, portanto, de parâmetro para a análise de propósitos práticos reais, objetos do estudo apresentados mais a seguir, logo após os aspectos metodológicos descritos abaixo.

\section{METODOLOGIA}

No sentido de se atingir o objetivo geral deste trabalho, isto é, analisar os propósitos e a eficácia de práticas de Responsabilidade Social de indústrias cearenses participantes do Prêmio SESI de Qualidade no Trabalho (PSQT), decidiu-se por uma metodologia constituída pelos seguintes elementos: natureza, nível, delineamento do campo empírico e estratégias de coleta e análise de dados.

Quanto à natureza, este trabalho pode ser caracterizado como qualitativo, uma vez que centrou suas atenções sobre a análise de dados linguísticos (GIL, 1996), isto é, de práticas de Responsabilidade Social apresentadas sob a forma de textos redigidos por seus próprios praticantes. No que se refere ao nível, trata-se de uma pesquisa explicativa, uma vez que buscou, à luz dos propósitos recomendados pela literatura especializada, inferir sobre determinado fenômeno (RICHARDSON, 1999), isto é, sobre o que querem as empresas ao se envolverem com a temática da Responsabilidade Social.
Em relação ao campo empírico, optou-se por 74 práticas de 52 indústrias cearenses participantes do Prêmio SESI de Qualidade no Trabalho (PSQT) no ano de 2012. A escolha de indústrias participantes do PSQT se deu por conta dos seguintes motivos:

a) São empresas que decidiram concorrer a um prêmio que avalia suas práticas sob a perspectiva da Responsabilidade Social;

b) São empresas que, para concorrer a tal prêmio, deram-se ao trabalho de escrever e submeter suas próprias práticas de Responsabilidade Social e;

c) Tais práticas, escritas e submetidas a partir de formulário padrão, puderam ser acessadas e utilizadas como objeto de pesquisa documental (GIL, 1996).

Uma vez coletados, os dados foram categorizados por meio da análise de conteúdo de grade fechada (BARDIN, 1977). As categorizações se deram em três etapas:

a) Filtraram-se os propósitos declarados das práticas em questão, explicitados nos arquivos em campo denominado "principais objetivos";

b) Deduziram-se os propósitos tácitos a partir de leituras rigorosas dos arquivos como um todo, sempre sob o questionamento de quais os porquês dos objetivos declarados e;

c) Compararam-se os propósitos empíricos identificados com os propósitos teóricos deduzidos da ISO 26000 no terceiro capítulo deste trabalho.

Os resultados encontrados foram detalhados no quinto capítulo a seguir.

\section{ANÁLISE DE DADOS E RESULTA- DOS}

Este capítulo faz uma análise dos propósitos de 74 práticas de Responsabilidade Social realizadas e escritas por 52 indústrias de diferentes segmentos participantes da última edição do PSQT, realizada em 2012, conforme o Gráfico 1 abaixo. 
QUANTIDADE DE EMPRESAS

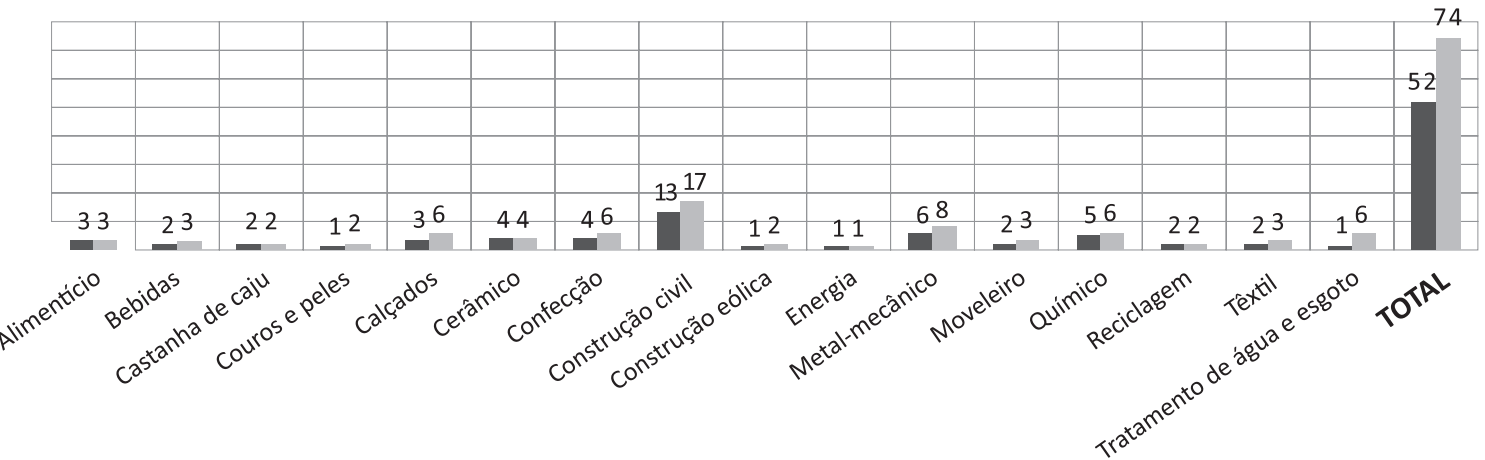

Gráfico 1 - Quantidade de empresas por segmento e de práticas inscritas no PSQT

Fonte: dados da pesquisa (2014).

O PSQT tem como objetivo principal estimular as empresas industriais brasileiras para que incorporem a Responsabilidade Social como parte integrante de suas estratégias empresariais, mediante o reconhecimento e a difusão de boas práticas.

Para tanto, recebe e avalia práticas inscritas por indústrias a partir de formulário padrão que contem os seguintes campos principais: nome da prática, histórico e justificativa, principais objetivos, abrangência e beneficiários, resultados obtidos, estrutura, mecanismo e recursos humanos e financeiros, aspectos de ino- vação, período de operacionalização, potencial de replicação e outras evidências e informações. Após rigorosas leituras de tais práticas e reuniões de consenso das percepções individuais, os autores deste trabalho puderam identificar os principais propósitos das indústrias investigadas ao se envolverem com a temática da Responsabilidade Social, comparando-os com os propósitos recomendados pela literatura, conforme o Quadro 2 abaixo.

\begin{tabular}{|l|c|l|l|}
\hline $\begin{array}{c}\text { Propósitos empíricos } \\
\text { identificados }\end{array}$ & Ocorrências & $\begin{array}{c}\text { Propósitos teóricos mais } \\
\text { aproximados }\end{array}$ & $\begin{array}{l}\text { Comparativo entre propó- } \\
\text { sitos empíricos e teóricos }\end{array}$ \\
\hline $\begin{array}{l}\text { Proporcionar um ambiente } \\
\text { de trabalho agradável, } \\
\text { seguro e saudável. }\end{array}$ & 52 & $\begin{array}{l}\text { A preocupação com o am- } \\
\text { biente de trabalho e com o } \\
\text { Oferecer condições dignas de } \\
\text { trabalho. }\end{array}$ & $\begin{array}{l}\text { te, mas quase sempre é meio } \\
\text { para fins como produtividade. }\end{array}$ \\
\hline $\begin{array}{l}\text { Promover a qualidade de } \\
\text { vida no trabalho. }\end{array}$ & 15 & $\begin{array}{l}\text { Oferecer condições dignas de } \\
\text { trabalho. }\end{array}$ & $\begin{array}{l}\text { Normalmente é meio para } \\
\text { fins como produtividade. }\end{array}$ \\
\hline $\begin{array}{l}\text { Promover a qualificação } \\
\text { profissional dos trabalhado- } \\
\text { res. }\end{array}$ & 26 & $\begin{array}{l}\text { Oferecer condições dignas de } \\
\text { trabalho; desenvolver compe- } \\
\text { tências internas para a Res- } \\
\text { ponsabilidade Social. }\end{array}$ & $\begin{array}{l}\text { É meio para fins como qua- } \\
\text { lidade e produtividade. }\end{array}$ \\
\hline $\begin{array}{l}\text { Conscientizar a comunidade } \\
\text { quanto às questões socioam- } \\
\text { bientais. }\end{array}$ & 18 & $\begin{array}{l}\text { Envolver e desenvolver a co- } \\
\text { munidade onde opera; infor- } \\
\text { mar e conscientizar as partes } \\
\text { interessadas quanto à Respon- }\end{array}$ & $\begin{array}{l}\text { Por vezes, decorre do altru- } \\
\text { ísmo da alta direção; é tam- } \\
\text { sém causado pelo modismo } \\
\text { atual da área de educação } \\
\text { ambiental. }\end{array}$ \\
\hline
\end{tabular}




\begin{tabular}{|c|c|c|c|}
\hline $\begin{array}{l}\text { Melhorar a qualidade dos } \\
\text { processos internos. }\end{array}$ & 16 & $\begin{array}{l}\text { Obter resultados eficazes com as } \\
\text { ações de Responsabilidade Social; } \\
\text { desenvolver competências internas } \\
\text { para a Responsabilidade Social. }\end{array}$ & $\begin{array}{l}\text { Trata-se exclusivamente da } \\
\text { geração de eficiência pro- } \\
\text { dutiva. }\end{array}$ \\
\hline $\begin{array}{l}\text { Realizar gestão participativa } \\
\text { como foco em resultados. }\end{array}$ & 16 & $\begin{array}{l}\text { Ser transparente em suas deci- } \\
\text { sões e atividades; oferecer con- } \\
\text { dições dignas de trabalho; obter } \\
\text { resultados eficazes com as ações } \\
\text { de Responsabilidade Social. }\end{array}$ & $\begin{array}{l}\text { É meio para gerar compro- } \\
\text { metimento do trabalhador e } \\
\text { aumento da produtividade. }\end{array}$ \\
\hline Motivar os funcionários. & 12 & $\begin{array}{l}\text { Oferecer condições dignas de } \\
\text { trabalho; obter resultados efi- } \\
\text { cazes com as ações de Res- } \\
\text { ponsabilidade Social. }\end{array}$ & $\begin{array}{l}\text { É meio para comprometi- } \\
\text { mento e produtividade. }\end{array}$ \\
\hline $\begin{array}{l}\text { Desenvolver projetos so- } \\
\text { ciais para a comunidade. }\end{array}$ & 15 & $\begin{array}{l}\text { Envolver e desenvolver a co- } \\
\text { munidade onde opera. }\end{array}$ & $\begin{array}{l}\text { Decorre de sentimento al- } \\
\text { truísta da alta direção e de } \\
\text { engajamento técnico dos } \\
\text { gestores; tem pretensão de } \\
\text { promoção da reputação. }\end{array}$ \\
\hline $\begin{array}{l}\text { Obter alinhamento estraté- } \\
\text { gico. }\end{array}$ & 10 & $\begin{array}{l}\text { Ser transparente em suas deci- } \\
\text { sões e atividades; decidir com } \\
\text { base nos princípios de Res- } \\
\text { ponsabilidade social. }\end{array}$ & $\begin{array}{l}\text { É meio para gerar compro- } \\
\text { metimento e produtividade. }\end{array}$ \\
\hline $\begin{array}{l}\text { Reduzir acidentes e doenças } \\
\text { no trabalho. }\end{array}$ & 10 & $\begin{array}{l}\text { Conhecer e cumprir a lei e os re- } \\
\text { gulamentos aplicáveis; oferecer } \\
\text { condições dignas de trabalho. }\end{array}$ & $\begin{array}{l}\text { É meio para gerar produti- } \\
\text { vidade e evitar penalidades } \\
\text { legais. }\end{array}$ \\
\hline $\begin{array}{l}\text { Promover a qualidade de vida } \\
\text { e o bem-estar da comunidade. }\end{array}$ & 12 & $\begin{array}{l}\text { Envolver e desenvolver a co- } \\
\text { munidade onde opera. }\end{array}$ & $\begin{array}{l}\text { Decorre de sentimento al- } \\
\text { truísta da alta direção e de } \\
\text { engajamento técnico dos } \\
\text { gestores; tem pretensão de } \\
\text { promoção da reputação. }\end{array}$ \\
\hline $\begin{array}{l}\text { Atender às exigências do } \\
\text { consumidor. }\end{array}$ & 04 & $\begin{array}{l}\text { Oferecer informações precisas } \\
\text { e contratos justos e promover } \\
\text { a acessibilidade de produtos e } \\
\text { o consumo sustentável. }\end{array}$ & $\begin{array}{l}\text { É meio para a melhoria da } \\
\text { qualidade de produtos e } \\
\text { consequente aumento do } \\
\text { volume de vendas. }\end{array}$ \\
\hline $\begin{array}{l}\text { Otimizar recursos produti- } \\
\text { vos. }\end{array}$ & 04 & $\begin{array}{l}\text { Obter resultados eficazes com } \\
\text { as ações de Responsabilidade } \\
\text { Social; desenvolver compe- } \\
\text { tências internas para a Res- } \\
\text { ponsabilidade Social. }\end{array}$ & $\begin{array}{l}\text { Trata-se exclusivamente da } \\
\text { geração de eficiência pro- } \\
\text { dutiva e eficácia organiza- } \\
\text { cional. }\end{array}$ \\
\hline $\begin{array}{l}\text { Promover a inclusão social e } \\
\text { a cidadania. }\end{array}$ & 06 & $\begin{array}{l}\text { Respeitar os interesses de suas } \\
\text { partes interessadas; respeitar as } \\
\text { normas internacionais de com- } \\
\text { portamento; respeitar os direitos } \\
\text { humanos; reconhecer como legí- } \\
\text { timos os princípios da Responsa- } \\
\text { bilidade Social; Informar e cons- } \\
\text { cientizar as partes interessadas } \\
\text { quanto à Responsabilidade Social; }\end{array}$ & $\begin{array}{l}\text { Tem base altruísta, alinhan- } \\
\text { do-se, de fato, com os prin- } \\
\text { cípios da Responsabilidade } \\
\text { Social mais ligados aos as- } \\
\text { pectos estratégicos da orga- } \\
\text { nização. }\end{array}$ \\
\hline Aumentar a produtividade. & 03 & $\begin{array}{l}\text { Obter resultados eficazes com } \\
\text { as ações de Responsabilidade } \\
\text { Social. }\end{array}$ & $\begin{array}{l}\text { Trata-se exclusivamente da } \\
\text { geração de eficiência produ- } \\
\text { tiva e eficácia organizacional. }\end{array}$ \\
\hline
\end{tabular}




\begin{tabular}{|c|c|c|c|}
\hline $\begin{array}{l}\text { Desenvolver tecnologias } \\
\text { sustentáveis. }\end{array}$ & 03 & $\begin{array}{l}\text { Desenvolver competências internas } \\
\text { para a Responsabilidade Social. }\end{array}$ & $\begin{array}{l}\text { Trata-se exclusivamente da ge- } \\
\text { ração de eficiência produtiva. }\end{array}$ \\
\hline $\begin{array}{l}\text { Melhorar o desempenho fi- } \\
\text { nanceiro. }\end{array}$ & 03 & $\begin{array}{l}\text { Obter resultados eficazes com } \\
\text { as ações de Responsabilidade } \\
\text { Social. }\end{array}$ & $\begin{array}{l}\text { Trata-se exclusivamente da } \\
\text { geração de eficácia organi- } \\
\text { zacional. }\end{array}$ \\
\hline $\begin{array}{l}\text { Melhorar a imagem institu- } \\
\text { cional. }\end{array}$ & 02 & $\begin{array}{l}\text { Obter o reconhecimento da } \\
\text { sociedade por suas práticas so- } \\
\text { cialmente responsáveis. }\end{array}$ & $\begin{array}{l}\text { Tem mera preocupação com } \\
\text { a reputação. }\end{array}$ \\
\hline $\begin{array}{l}\text { Melhorar a qualidade do } \\
\text { produto. }\end{array}$ & 01 & $\begin{array}{l}\text { Oferecer informações precisas } \\
\text { e contratos justos e promover } \\
\text { a acessibilidade de produtos e } \\
\text { o consumo sustentável. }\end{array}$ & $\begin{array}{l}\text { É meio para o aumento do } \\
\text { volume de vendas, da efici- } \\
\text { ência produtiva e da eficácia } \\
\text { organizacional. }\end{array}$ \\
\hline Atender a legislação vigente. & 01 & $\begin{array}{l}\text { Conhecer e cumprir a lei e os } \\
\text { regulamentos aplicáveis. }\end{array}$ & $\begin{array}{l}\text { É mero meio de evitar as pe- } \\
\text { nalidades legais. }\end{array}$ \\
\hline $\begin{array}{l}\text { Desenvolver a gestão am- } \\
\text { biental. }\end{array}$ & 01 & $\begin{array}{l}\text { Mitigar os impactos ambientais } \\
\text { de suas decisões e atividades. }\end{array}$ & $\begin{array}{l}\text { É mero meio de evitar as pe- } \\
\text { nalidades legais. }\end{array}$ \\
\hline Mitigar impactos ambientais. & 01 & $\begin{array}{l}\text { Mitigar os impactos ambientais } \\
\text { de suas decisões e atividades. }\end{array}$ & $\begin{array}{l}\text { É meio de evitar as penali- } \\
\text { dades legais. }\end{array}$ \\
\hline $\begin{array}{l}\text { Gerar renda para os funcio- } \\
\text { nários. }\end{array}$ & 01 & $\begin{array}{l}\text { Oferecer condições dignas de } \\
\text { trabalho. }\end{array}$ & $\begin{array}{l}\text { É meio de aumento da pro- } \\
\text { dutividade. }\end{array}$ \\
\hline
\end{tabular}

Quadro 2 - Comparativo entre propósitos empíricos e teóricos de RSE

Fonte: dados da pesquisa (2014).

Com base em tal comparativo, torna-se possível realizar algumas inferências:

Conforme anteriormente assinalado, 52 empresas e 74 práticas respectivas de RSE foram analisadas. Destas, 232 propósitos foram identificados. Em termos de Stakeholders, 158 se voltaram para os trabalhadores, 51 para a comunidade, 15 para os acionistas, cinco para os consumidores e três para o governo e para o meio ambiente, no tocante ao atendimento às regulamentações ambientais.

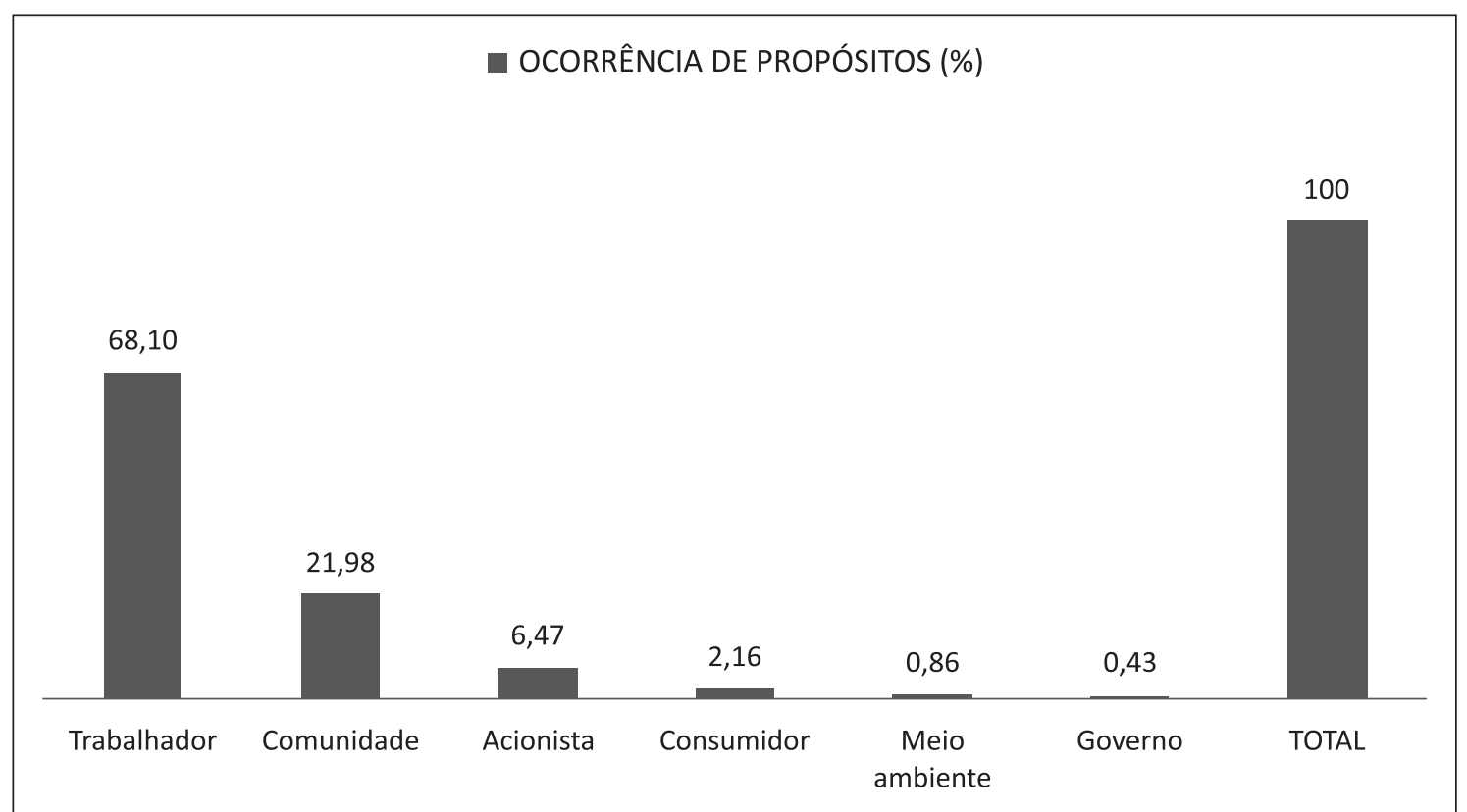

Gráfico 2 - Ocorrências de propósitos de RSE por Stakeholders

Fonte: dados da pesquisa (2014). 
O Gráfico 2 acima apresenta, em números percentuais, tal distribuição de ocorrência de propósitos por Stakeholders. Nota-se que os propósitos relacionados aos trabalhadores se referem quase sempre ao aumento da produtividade, sendo indiretamente, portanto, propósitos dos acionistas, que, nesta perspectiva, não ficam alocados em terceira posição, mas em primeira.

Em termos de conteúdo, os 232 propósitos se distribuíram da seguinte forma: $101 \mathrm{se}$ voltaram para a questão da produtividade no trabalho, 54 para o comprometimento do trabalhador (normalmente, como meio para o aumento da produtividade) e 25 para o aumento da qualidade dos processos e dos produtos; 21 decorreram de sentimentos altruístas dos decisores; 11 se voltaram para a promoção da reputação da empresa; nove decorreram de simples modismos gerenciais; oito se voltaram para o cumprimento de leis trabalhistas e ambientais; e somente três se relacionaram com a perspectiva estratégica e de gestão organizacional. Tais ocorrências de propósitos distribuídos por seus conteúdos estão representadas em termos percentuais pelo Gráfico 3, a seguir.
Em outras palavras, e atendendo ao objetivo principal deste trabalho, pode-se afirmar que o que as empresas, de fato, querem quando se trata de Responsabilidade Social, em ordem de prioridade e recorrência, é:

a) Aumentar a produtividade do trabalho;

b) Comprometer o trabalhador;

c) Melhorar a qualidade de processos e produtos

d) Realizar ações de filantropia para a comunidade;

e) Promover sua reputação;

f) Implementar estratégias que estão na moda;

g) Atender à Lei, evitando penalidades $\mathrm{e}$;

h) Incorporar os princípios da RSE à estratégia empresarial.

Destaca-se o fato de que as indústrias estão enormemente preocupadas em comprometer seus colaboradores em torno de seus objetivos estratégicos, na perspectiva de maximizar a produtividade e, em última instância, a lucratividade. Além disso, quase sempre se adotam

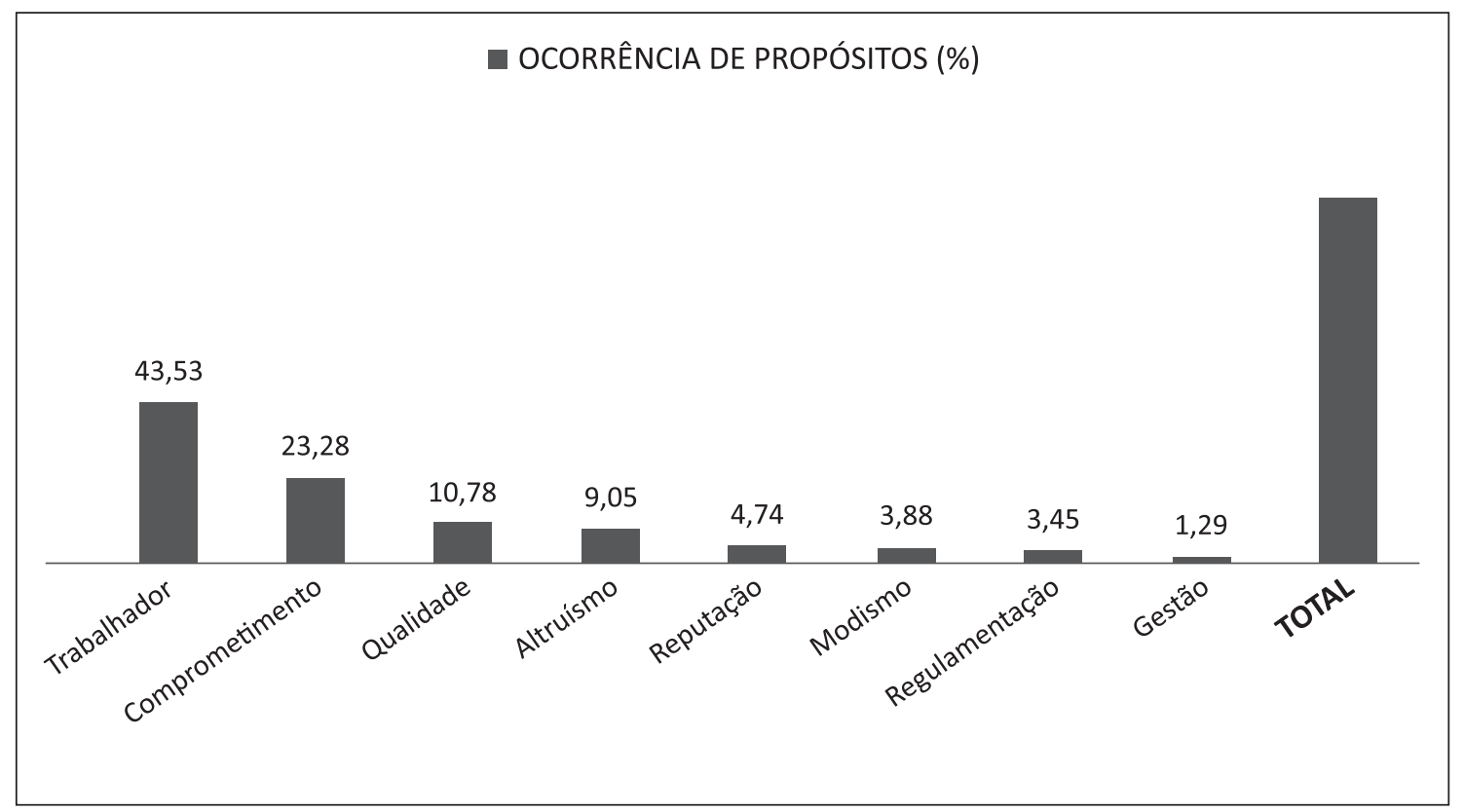

Gráfico 3 - Ocorrências de propósitos de RSE por

conteúdo

Fonte: dados da pesquisa (2014). 
ações paliativas e reativas, focadas na qualidade de vida e no bem-estar humano apenas como meios para o aumento da eficiência.

Outro detalhe é que as práticas são, em geral, realizadas como projetos específicos, voltados para determinada parte interessada, não estando, portanto, pautadas pelos propósitos teóricos mais ligados aos aspectos estratégicos da empresa, como "responsabilizar-se por suas ações" e "comportar-se eticamente", ambos sem nenhuma ocorrência.

A Filantropia se destaca como uma prática com frequência relativamente alta, evidenciando iniciativas pessoais dos acionistas, desatreladas de seus negócios.

Merece destaque, por outro lado, apesar da baixíssima frequência, o propósito empírico "Promover a inclusão social e a cidadania", por retratar, de fato, grande parte dos princípios da Responsabilidade Social.

Por fim, pode-se perceber a influência da teoria sobre a prática, pois, mesmo nos casos em que se busca privilegiar determinada parte interessada, como os acionistas, em detrimento de outras, os princípios de Responsabilidade Social ao menos inspiram os discursos das empresas pesquisadas, a ponto de se ter para cada propósito empírico identificado um propósito teórico semelhante correspondente.

\section{CONSIDERAÇÕES FINAIS}

Este trabalho cumpriu seu objetivo geral na medida em que apresentou e analisou, à luz da teoria especializada, os propósitos de indústrias cearenses engajadas com a temática da Responsabilidade Social.

Pôde-se evidenciar como resultados principais que as empresas se inspiram nos princípios da Responsabilidade Social, mas quase sempre os adaptam aos interesses dos acionistas, atuando a partir de projetos paliativos voltados para determinada demanda, e não para a identificação e para o engajamento das partes interessadas como um todo.

Como estudos futuros, sugere-se, dada a riqueza das práticas analisadas, outras pers- pectivas analíticas para além dos propósitos organizacionais, como a eficácia, a eficiência, dentre outras.

\section{AN ANALYSIS OF THE PURPOSES OF CORPORATE SOCIAL RESPONSIBILITY PRACTICES OF INDUSTRIES FROM THE STATE OF CEARÁ THAT PARTICIPATE IN SESI'S QUALITY AT WORK AWARD}

\section{ABSTRACT}

The main objective of this study is to analyze the purposes of Corporate Social Responsibility practices of industries from the state of Ceará that participate in SESI's Quality at Work Award (abbreviated as PSQT in Portuguese); these companies: a) decided to make an effort to run for this award to evaluate their Social Responsibility practices; b) run for this award by describing and submitting their own Social Responsibility practices; and c) had their practices assessed and used as the object for a documental research and content analysis in this work. The main results show that industries that took part in this investigation are inspired by the purposes recommended by the theory, but normally adapt them to their shareholders perspectives.

Keywords: Corporate social responsibility. Sustainable development. Shareholders. Stakeholders.

1 Artigo apresentado ao X Congresso Mundial de Administração, no ano de 2015, na cidade de Porto - Portugal. Autores: Raphael de Jesus Campos de Andrade, Laodicéia Amorim Weersma e Eleazar de Castro Ribeiro.

\section{REFERÊNCIAS}

ALVES, E. A. Dimensões da responsabilidade social da empresa: uma abordagem desenvolvida a partir da visão de Bowen. Revista de Administração de São Paulo, São Paulo, v. 38, n. 1, p. 37-45, jan./fev./mar. 2003. 
BARBIERI, J. C.; CAJAZEIRA, J. E. R. Responsabilidade social empresarial e empresa sustentável: da teoria à prática. São Paulo: Saraiva, 2009.

BARDIN, L. Análise do conteúdo. Lisboa: Edições 70, 1977.

CAMPANARIO, M. A.; MORETTI, S. L. A. A produção intelectual brasileira em responsabilidade social empresarial - RSE sob a ótica da bibliometria. Revista de Administração Contemporânea, Curitiba, v. 13, p. 68-86, jun. 2009. Edição Especial.

CAMPOS FILHO, L. A. N.; PEREIRA, W. A. Investigação sobre as semelhanças entre os modelos conceituais da responsabilidade social corporativa. Revista de Gestão Social e Ambiental, São Paulo, v. 1, n. 1, p. 3-18, jan./abr. 2007.

CARROLL, A. B. A three-dimensional conceptual model of corporate performance. Academy of Management Review, United States, v. 4, n. 4, p. 17-25, Oct. 1979.

Corporate social responsibility. Business and Society, United States, v. 38, n. 3, p. 268-295, set. 1999.

ELKINGTON, J. Canibais com garfo e faca. São Paulo: Makron Books, 2001.

FRIEDMAN, M. The social responsibility of business is to increase its profits. New York Times, New York, 13 Sept. 1970.

FREEMAN, R. E. Strategic management: a stakeholder approach. Boston: Pitman, 1984.

GARRIGA, E.; MELÉ, D. Corporate social responsibility theories: mapping the territory. Journal of business Ethics, Netherlands, v. 53, p. 54-71, 2004.

GIL, A. C. Métodos e técnicas de pesquisa so- cial. 5. ed. São Paulo: Atlas, 1996.

GOMES, A.; MORETTI, S. L. A. A responsabilidade e o social: uma discussão sobre o papel das empresas. São Paulo: Saraiva, 2007.

KAMEL, J. A. N.; RESENDE, M. S. R. Diálogo com stakeholders: ideias e experiências para a sua viabilidade. Revista Gestão Industrial, Paraná, v. 3, n. 1, p. 111-122, 2007.

KRAMER, M.; PORTER, M. E. The competitive advantage of corporate philanthropy. Harvard Business Review, United States, Dec. 2002.

Strategy and society: the link between competitive advantage and corporate social responsibility. Harvard Business Review, United States, Dec. 2006

MCWILLIAMS, A.; SIEGEL, D. Corporate social responsibility: a theory of the firm perspective. Academy of Management Review, United States, v. 26, n. 1, p. 117-127, 2001.

RICHARDSON, R. J. Pesquisa social: métodos e técnicas. 3. ed. São Paulo: Atlas, 1999. 